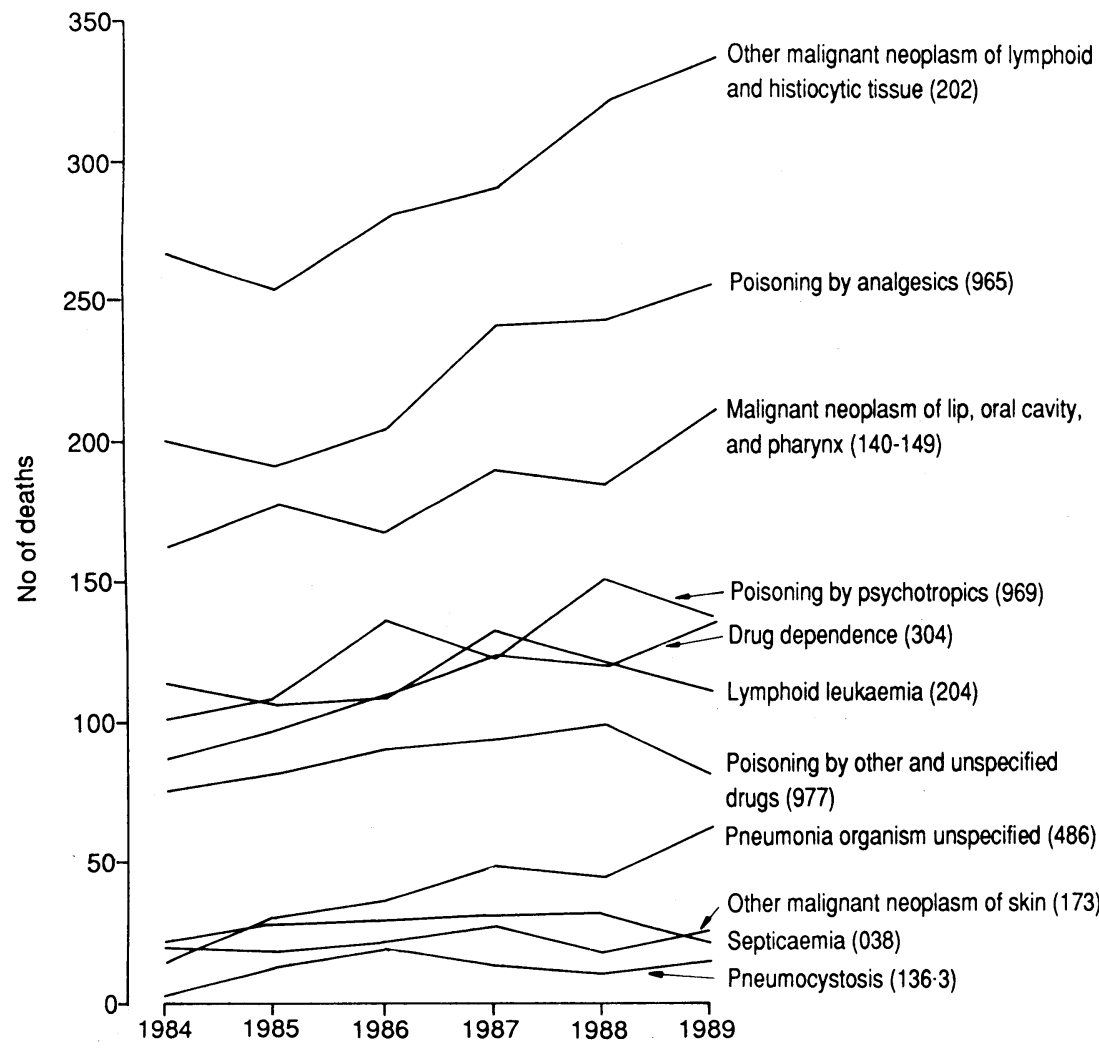

Number of deaths from selected HIV related causes (International Classification of Diseases codes) in men aged 15-54 in England and Wales

disease suggests that at least part of the increase is HIV related. This is supported by a report of the increased risk of suicide among people with AIDS in New York. ${ }^{2}$

The increasing number of reported deaths due to opportunistic diseases might result from improved diagnosis or immunosuppressive therapy. If this were so it would be expected that similar changes in death rates would be apparent among men of each marital state and among women. However, death rates from lymphoma (ICD 202) have increased among single men of all age groups from 15 to 44 years but show no similar increase among men of other marital states or among women. Death rates from pneumonia increased fourfold between the two three year periods 1984-6 and 1987-9 among single men aged 30-44 years and are 10 times those for other men and for women (unpublished data).

Men followed up in the study may have been known to be HIV positive but this information may not have been available to the person who replied to the inquiry. However, over $85 \%$ of people for whom AIDS or HIV infection is stated as the cause of death die in hospital, so any underreporting of positive tests to the patient's general practitioner is unlikely to have influenced these results. In addition, every man included in the follow up study who had been reported to CDSC was known by the respondent to be HIV positive.

In conclusion, the results have implications for the carers of people with these HIV related conditions. They also suggest that the full extent of the HIV epidemic has not yet been recognised. The study was, however, based on small numbers and further work needs to be done to verify the findings.

I thank all those clinicians and coroners who took so much trouble in replying to the inquiry letter.

1 McCormick A. Excess mortality associated with HIV epidemic in England and Wales. BMf 1991;302:1375-6.

2 Marzuk PM, Tierney H, Tardiff K, Grass EM, Morgan EB, Hsu M-A, et al. Increased risk of suicide in persons with AIDS. FAMA 1988;259:1333-7.

(Accepted 18 April 1991)

\title{
Single dose cabergoline versus bromocriptine in inhibition of puerperal lactation: randomised, double blind, multicentre study
}

\author{
European Multicentre Study Group for Cabergoline in Lactation Inhibition
}

Report prepared by

Professor R Rolland and Drs

G Piscitelli, C Ferrari, and A

Petroccione.

Members of the group are listed at the end of the paper.

Correspondence to: Professor R Rolland, Department of Obstetrics and Gynaecology, St Radboud University Hospital, $6500 \mathrm{H} \mathrm{B}$

Nijmegen, The

Netherlands.

BMf 1991;302:1367-71
Abstract

Objective-To compare the efficacy and safety of a single dose of $1 \mathrm{mg}$ of cabergoline with that of bromocriptine $2.5 \mathrm{mg}$ twice daily for 14 days in the inhibition of puerperal lactation.

Design-Prospective, randomised, double blind, parallel group, multicentre study.

Setting-University or hospital departments of obstetrics and gynaecology in different European countries.

Subjects-272 puerperal women not wishing to lactate (136 randomised to each drug).

Interventions-Women randomised to cabergoline received two $0.5 \mathrm{mg}$ tablets of cabergoline and one placebo tablet within 27 hours after delivery and then placebo twice daily for 14 days. Those randomised to bromocriptine received $2.5 \mathrm{mg}$ of bromocriptine and two placebo tablets within 27 hours and then $2.5 \mathrm{mg}$ of bromocriptine twice daily for 14 days.

Main outcome measures-Success of treatment (complete or partial) according to milk secretion, breast engorgement, and breast pain; rebound symptomatology; serum prolactin concentrations; and number of adverse events.

Results - Complete success was achieved in 106 of 136 women randomised to cabergoline and in 94 of 136 randomised to bromocriptine and partial success in 21 and 33 women respectively. Rebound breast symptomatology occurred respectively in five and 23 women with complete success up to day 15 $(\mathbf{p}<0.0001)$. Serum prolactin concentrations dropped considerably with both drugs from day 2 to day 15 ; a prolactin secretion rebound effect was observed in women treated with bromocriptine. Adverse events were reported by 22 women receiving cabergoline and 36 receiving bromocriptine $(p=0.054)$, occurring mostly during the first treatment day.

Conclusion-A single $1 \mathrm{mg}$ dose of cabergoline is at least as effective as bromocriptine $2.5 \mathrm{mg}$ twice daily for 14 days in preventing puerperal lactation. Because of the considerably lower rate of rebound breast activity and adverse events and the simpler administration schedule cabergoline should be the drug of choice for lactation inhibition.

\section{Introduction}

Despite the well known advantages of breast feeding, prevention or suppression of milk production may be indicated on medical or personal grounds.' Although tight binders may result in the suppression of puerperal lactation, appreciable breast pain and milk secretion frequently occur, especially in multiparous women. ${ }^{2}$ Oestrogens given alone or in combination with 
androgens show variable efficacy $(40-100 \%)$, are associated with a high rate $(14-47 \%)$ of rebound lactation, ${ }^{3}$ and enhance the risk of thrombosis or pulmonary embolism, or both, during the puerperium. ${ }^{45}$ Since their introduction in 1972 dopaminergic drugs like bromocriptine have become the treatment of choice for preventing lactation because of their effective suppression of prolactin release from the pituitary. ${ }^{6}$ Data are available suggesting that galactopoiesis requires a serum prolactin threshold concentration of about $25 \mu \mathrm{g} / \mathrm{l}^{7}$ Bromocriptine given as $2.5 \mathrm{mg}$ twice daily for 14 days successfully prevents lactation in from $70 \%$ to more than $90 \%$ of women in the puerperium. ${ }^{168}$ However, this treatment is also associated with rebound breast activity in the third week postpartum in $18 \%$ to $40 \%$ of women due to the rapid rebound in serum prolactin concentration. ${ }^{9}$ Furthermore, adverse reactions occur in about $23 \%$ of women in the puerperium within the recommended dosage range of bromocriptine. Other ergoline derivatives like metergoline and lisuride are equally as effective or less effective than bromocriptine in the indication of inhibition of lactation. ${ }^{11}$ Recently an intramuscular depot preparation of bromocriptine has been reported successful in this indication in $88 \%$ of puerperal women. ${ }^{12}$

Cabergoline (1-[(6-allylergolin-8- $\beta-y l)]-1-[3-($ dimethylamino [propyl]-3-ethylurea) is a novel ergoline derivative with potent and long lasting prolactin lowering effect. This effect has been shown both in vitro and in vivo and also in healthy volunteers and hyperprolactinaemic subjects. ${ }^{1314}$ In a pilot study testing cabergoline in the inhibition of lactation $0.8 \mathrm{mg}$ taken within 24 hours of delivery prevented lactation in all of eight women. ${ }^{15}$ Other data showed a dose response curve in the $0.5-1.0 \mathrm{mg}$ dose range ${ }^{16} ; 1 \mathrm{mg}$ of cabergoline was effective in preventing lactation in 36 of 40 women $(90 \%)$ with a rate of adverse events of $7 \cdot 5 \%$.

We compared the efficacy, tolerability, and safety of $1 \mathrm{mg}$ of cabergoline given as a single dose within 27 hours of delivery with that of bromocriptine $2.5 \mathrm{mg}$ twice daily for 14 days in a randomised, double blind, parallel group, multinational study.

\section{Subjects and methods}

Between July 1988 and August 1989, 272 women in the puerperium who did not wish to breast feed their offspring for personal or medical reasons agreed to enter the trial. The study was carried out in accordance with local regulations and the declaration of Heksinki in 12 European centres. All women gave their informed consent to the study. Women delivering at term who expected to be in hospital for at least three days after delivery and to be visited on day 15 either in hospital or at home entered the study. Women with a history of agalactia or hypogalactia, drug allergy, intrauterine fetal death, pre-eclampsia, or liver or kidney impairment and those who had concomitant acute diseases were excluded from the study.

\section{TEST TREATMENTS AND ALLOCATION}

Treatments were given double blind, using the double dummy technique, according to a randomised sequence balanced within each centre. The drugs were provided by Farmitalia Carlo Erba in individualised patient kits, which were assigned by the doctor according to the patient's order of entry to the study. Subjects randomised to cabergoline received two tablets of $0.5 \mathrm{mg}$ of cabergoline and one placebo tablet and then placebo twice daily up to day 14 ; subjects randomised to bromocriptine received $2.5 \mathrm{mg}$ of bromocriptine and two placebo tablets followed by $2.5 \mathrm{mg}$ of bromocriptine twice daily for 14 days. The first treatment dose had to be given between 8am and 9am within 27 hours after delivery.

Compliance with dose regimens was assured by the presence of the doctor or a nurse for the first administration of the test drugs and during the hospital stay; the women were requested to return at the visit on day 15 any unused tablet(s).

\section{EFFICACY EVALUATION}

The effectiveness of test treatments in preventing lactation was evaluated daily during the hospital stay and at the visit on day 15 . The woman herself assessed her breasts daily by using a self evaluation form. The presence of breast symptoms from day 16 to 21 was recorded on day 21 either by a further visit or by a telephone call. The success of treatment was evaluated both on day 3 (before hospital discharge) and on day 15. The efficacy variables considered were spontaneous milk secretion, breast engorgement, and breast pain. Table I shows the grading of severity of these signs and symptoms.

Complete success was defined as absence of breast signs and symptoms except for mild spontaneous milk secretion, which must be regarded as physiological as the breasts have already produced some milk at the end of pregnancy.

Partial success was defined as presence of any moderate milk secretion or mild to moderate breast pain, or both, or breast engorgement at any time; failure was defined as the presence, even for only one day, of severe breast engorgement or pain, or abundant milk secretion. If present, breast symptomatology from day 16 to day 21 was defined as rebound lactation alone in subjects with complete success on day 15 . The absence of breast activity during the entire observation period of 21 days (that is complete success on day 15 without rebound symptomatology on days 16-21) was used as an additional criterion of efficacy.

Serum prolactin concentrations were monitored by radioimmunoassay on day 1 before the first administration of the drugs and on days 2,3 , and 15 in the morning as an ancillary biochemical criterion of efficacy of the test drugs. In one centre ( 40 women, 20 in each treatment group) serum prolactin concentrations were also evaluated on days 11,18 , and 21 .

\section{SAFETY EVALUATION}

Monitoring of safety variables included urine analysis and frequent measurements before and during treatment of blood pressure and heart rate, platelet count, and blood concentrations of urea, aspartate aminotransferase, glutamic-pyruvic transaminase, lactic dehydrogenase, alkaline phosphatase, glucose, and creatinine. The occurrence of adverse events was investigated daily during hospital stay and on day 15. Severity of adverse events was graded as: mildsymptoms or signs the subjects can easily cope with; moderate-the event worries the subject but not the doctor; or severe-the subject and the doctor agree that the woman's quality of life may be really threatened by the event. The possible relation of adverse events to the test drugs was defined as unknown, doubtful, possible, probable, or definite.

\section{STATISTICAL METHODS}

The effectiveness of the treatments was based on the rate of complete success on day 15 calculated according to the intention to treat analysis. To ascertain whether cabergoline was at least as effective as bromocriptine in inhibiting puerperal lactation the system whereby the null hypothesis stated that the success rate of bromocriptine minus that of cabergoline was greater than or equal to $0 \cdot 1(10 \%)$ and the alternative hypothesis that it was less than $0 \cdot 1$ was used.

According to these hypotheses and assuming a 
TABLE I-Rating scale for measures of efficacy of treatment with cabergoline or bromocriptine in inhibiting lactation

\begin{tabular}{|c|c|c|c|}
\hline Intensity of sign/symptom & Spontaneous milk secretion & Breast pain & Breast engorgement \\
\hline Mild & A few drops for $\leqslant 3$ days & Easily bearable & $\begin{array}{l}\text { Tenderness only on } \\
\text { palpation }\end{array}$ \\
\hline Moderate & $\begin{array}{l}\text { A few drops for }>3 \text { days } \\
\text { or copious secretion for } \\
<3 \text { days }\end{array}$ & Tolerable with difficulty & $\begin{array}{l}\text { Bearable hardening and } \\
\text { spontaneous tenderness }\end{array}$ \\
\hline Abundant or severe & $\begin{array}{l}\text { Copious secretion for }>3 \\
\text { days }\end{array}$ & Analgesic drugs required & $\begin{array}{l}\text { Hardening and tenderness } \\
\text { interfering with normal } \\
\text { daily activity }\end{array}$ \\
\hline
\end{tabular}

success rate of $90 \%, \alpha=0 \cdot 05$, and $\beta=0 \cdot 20$, the required sample size was 112 women per treatment arm. ${ }^{17} \mathrm{We}$ had decided to conclude that the two drugs were equivalent if the success rate with cabergoline was not more than $10 \%$ inferior to that with bromocriptine. A continuity corrected one tailed $\chi^{2}$ at $\alpha=0.05$ was applied pooling all centres. ${ }^{18}$ The Mantel-Haenszel test was used additionally to adjust the between treatment comparison. ${ }^{19}$

A two tailed $\chi^{2}$ test was used to compare the rate of rebound breast symptomatology during days 16-21 as well as to compare the proportion of women without breast activity during the entire observation period of 21 days.

Mean serum prolactin concentrations at each evaluation time in the two treatment groups were compared by a two tailed Student's $t$ test for unpaired data after logarithmic transformation of raw data: the $\mathrm{p}$ value critical for significance was set to 0.007 , according to Bonferroni's procedure ${ }^{20}$ to take into account the multiplicity of the comparisons. Laboratory values (baseline $v$ days 3 and 15) were compared by Student's two tailed $t$ test for paired data. The frequency of adverse events in each treatment arm was compared by using a two tailed $\chi^{2}$ test.

\section{Results}

In all, 136 women in the puerperium were randomised to each treatment arm: demographic data, clinical history, and baseline features were comparable in the two groups (table II). Six women randomised to

TABLE II-Demographic and baseline data on 272 women in puerperium randomised to cabergoline or bromocriptine

\begin{tabular}{lcc}
\hline & $\begin{array}{c}\text { Cabergoline } \\
(\mathbf{n}=136)\end{array}$ & $\begin{array}{c}\text { Bromocriptine } \\
(\mathbf{n}=136)\end{array}$ \\
\hline Mean $(\mathrm{SD})$ age (years) & $28 \cdot 0(4 \cdot 5)$ & $28 \cdot 5(5 \cdot 0)$ \\
No primiparous & 52 & 53 \\
No multiparous & 84 & 83 \\
No with vaginal delivery & 121 & 111 \\
No with caesarean delivery & 15 & 25 \\
Mean $(\mathrm{SD})$ No of weeks of pregnancy & $39 \cdot 4(1 \cdot 3)$ & $39 \cdot 2(1 \cdot 3)$ \\
Mean $(\mathrm{SD})$ serum prolactin $(\mu \mathrm{g} / \mathrm{l})$ & $131 \cdot 3(68 \cdot 9)$ & $129 \cdot 9(70 \cdot 8)$ \\
\hline
\end{tabular}

cabergoline and eight randomised to bromocriptine stopped taking the drugs before day 14 (one and three, respectively, due to intolerance, two and three were lost to follow up, and three and two, because of other reasons). Thirty four women (18 taking cabergoline and 16 taking bromocriptine) received concomitant treatment that may have interfered with lactation (ergot derivatives in 28 and oral contraceptives in six, equally dispensed over the two groups). In one instance the code was broken before the end of the study for one woman taking cabergoline owing to an unexpected adverse event (hemianopia); the woman remained blind to the treatment.

\section{EFFICACY}

Complete success in inhibiting lactation was obtained in 106 of 136 women randomised to cabergoline $(78 \%)$ and in 94 of 136 randomised to bromocriptine (69\%), partial success in $21(15 \%)$ and $33(24 \%)$ women respectively, and failure (including subjects not completing the study protocol) in nine women (7\%) for each treatment. This suggests a slightly higher effectiveness of cabergoline. The statistical analysis performed according to Dunnet and Gent ${ }^{18}$ rejected the null hypothesis, thus indicating that if a difference exists between the two compounds it is unlikely to be more than $10 \%\left(\chi^{2}=11 \cdot 75, \mathrm{p}<0.001\right)$. The point estimate of the difference between bromocriptine and cabergoline was $-8 \cdot 82 \%$ (95\% confidence interval $-19 \cdot 25 \%$ to $1 \cdot 61 \%$ ), thus excluding an inferior effectiveness of cabergoline $\geqslant 10 \%$. The effectiveness of treatments as evaluated on day 3 (before hospital discharge) were $\mathbf{9 0 . 4 \%}$ for cabergoline and $83.8 \%$ for bromocriptine.

Evaluation of breast symptomatology during days 16-21 showed that no symptoms had recurred in 119 $(88 \%)$ and $95(70 \%)$ women in the cabergoline and bromocriptine groups respectively. Among subjects defined as having complete successes on day 15 , five (5\%) and $23(24 \%)$, respectively, presented with breast symptoms during the following week. This difference in rate of rebound between the two drugs was highly significant $\left(\chi^{2}=17 \cdot 03, p<0 \cdot 0001\right)$.

Efficacy as evaluated by the absence of breast activity during the entire observation period of 21 days was significantly better with cabergoline than with bromocriptine (101 $(74 \%)$ subjects taking cabergoline v $69(51 \%)$ bromocriptine, $\left.\chi^{2}=15.07, \mathrm{p}<0.0001\right)$. Serum prolactin concentrations declined considerably from $131 \cdot 3 \mu \mathrm{g} / \mathrm{l}$ to $18.9 \mu \mathrm{g} / \mathrm{l}$ in the cabergoline group and from $129.9 \mu \mathrm{g} / 1$ to $18.7 \mu \mathrm{g} / \mathrm{l}$ in the bromocriptine group. However, the reduction was more prompt after cabergoline (from $131.3 \mu \mathrm{g} / 1$ to $26 \cdot 3 \mu \mathrm{g} / \mathrm{l} v$ from $129.9 \mu \mathrm{g} / \mathrm{l}$ to $45 \cdot 5 \mu \mathrm{g} / \mathrm{l}$ respectively on day 2$)$. On day 15 the concentrations in those taking cabergoline were somewhat higher than in those taking bromocriptine $(28.4 \mu \mathrm{g} / \mathrm{l} v 18.7 \mu \mathrm{g} / \mathrm{l})$. Monitoring serum prolactin concentrations up to day 21 in a subset of 40 women showed a considerable prolactin rebound after day 15 only in women treated with bromocriptine, with significantly higher concentrations compared with those taking cabergoline (for day 18, $\mathrm{p}=0.0005$ ) (figure). The time to resumption of menses was comparable between the two groups (mean (SD) 46 (14.7) days, median 44 days for those taking cabergoline $v 49(17 \cdot 2)$ days, 48 days for those taking bromocriptine).

\section{SAFETY}

There were no significant differences in mean systolic and diastolic blood pressures and heart rate both between treatments and at each time of measurement. However, changes in blood pressure indicative

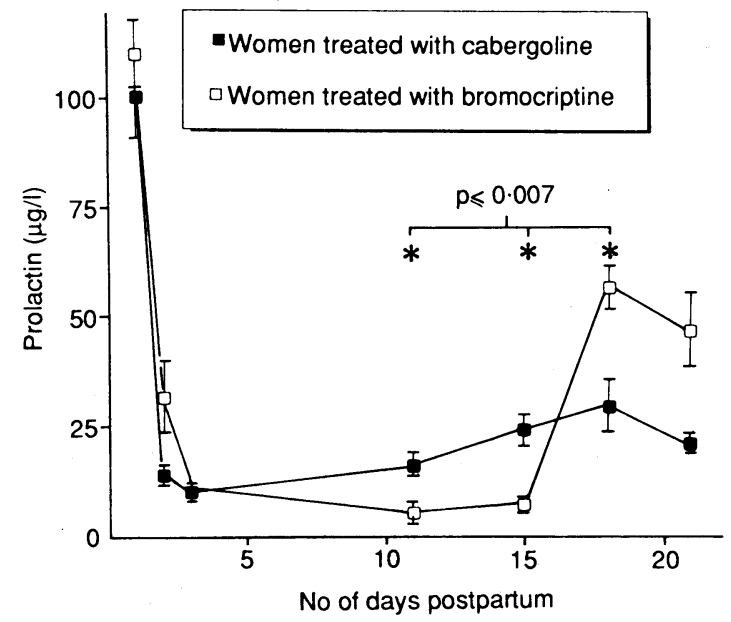

Mean (SE) serum prolactin concentration in 20 women treated with cabergoline and 20 treated with bromocriptine 
of orthostatic hypotension (a drop in systolic and diastolic blood pressure of $\geqslant 20 \mathrm{~mm} \mathrm{Hg}$ ) occurred in 10 women receiving cabergoline and 19 receiving bromocriptine, with symptoms possibly related to hypotension in four and 10 women respectively.

The results of the extensive laboratory tests showed normal changes in both treatment groups for the early puerperium. There was no significant difference between the groups and no interference of the drugs with the variables was shown.

Adverse events occurred in $22(16 \%)$ women randomised to cabergoline and in $36(27 \%)$ randomised to bromocriptine $(p=0.054)$, giving a total of 25 adverse events in those receiving cabergoline and 44 in

TABLE III - No of adverse events in women treated with cabergoline or bromocriptine

\begin{tabular}{lcc}
\hline & \multicolumn{2}{c}{ No of adverse events } \\
\cline { 2 - 3 } Sign/symptom & $\begin{array}{c}\text { Women receiving } \\
\text { cabergoline } \\
(\mathbf{n}=136)\end{array}$ & $\begin{array}{c}\text { Women receiving } \\
\text { bromocriptine } \\
(\mathrm{n}=136)\end{array}$ \\
\hline $\begin{array}{l}\text { Dizziness } \\
\text { Vertigo }\end{array}$ & 8 & 17 \\
Symptomatic hypotension & 1 & 2 \\
Palpitation & 1 & 1 \\
Headache & 7 & 6 \\
Nausea & 2 & 10 \\
Vomiting & 2 & 3 \\
Abdominal pain & 1 & 1 \\
Epigastric pain & 1 & 4 \\
Drowsiness & 2 & $44 \dagger$ \\
Other & $25 \star$ & \\
\hline Total & & \\
\hline
\end{tabular}

$\star$ Occurring in 22 women

tOccurring in 36 women.

those receiving bromocriptine (table III). Almost all events were typical of the adverse reactions with ergot derivatives, all were mild or moderate except for three severe side effects occurring in three women treated with bromocriptine (dizziness, vertigo, and symptomatic hypotension). Unexpected adverse events occurred in two women given cabergoline (epistaxis and transient hemianopia) and four given bromocriptine (facial paralysis, precordial pain, fever, and vaginal haemorrhage). The possible relation of these events with the drugs remains to be established as such events have not been previously described for this pharmacological class of compounds.

Treatment was stopped because of intolerance in three women given bromocriptine; one woman randomised to cabergoline stopped taking placebo on day 8 because of moderate epigastric pain. Most of the events occurred during the first day of treatment ( 14 of 25 in those taking cabergoline and 30 of 44 in those taking bromocriptine). Though some women reported either persistence of the symptoms during consecutive days or late occurrence of adverse events, a pronounced decline of the rate of symptoms occurred from day 2 , reaching very low values after day 3, particularly in those taking cabergoline (table IV)

events over entire study period

\begin{tabular}{ccc}
\hline & $\begin{array}{c}\text { No } \\
\text { receiving }\end{array}$ & $\begin{array}{c}\text { No } \\
\text { receiving } \\
\text { bromo- } \\
\text { criptine } \\
\text { No of days cabergoline } \\
\text { postpartum }\end{array}$ \\
$(\mathbf{n}=136)$ & $\mathbf{n}=136)$ \\
\hline 1 & 14 & 30 \\
2 & 9 & 25 \\
3 & 8 & 18 \\
4 & 3 & 11 \\
5 & 1 & 8 \\
6 & 1 & 8 \\
7 & 2 & 8 \\
8 & 2 & 8 \\
9 & 3 & 8 \\
10 & 3 & 7 \\
11 & 3 & 6 \\
12 & 3 & 6 \\
13 & 2 & 6 \\
14 & 2 & 7 \\
15 & 1 & 3 \\
16 & & 1 \\
\hline
\end{tabular}
success up to the end of the observation period days after delivery) for cabergoline compared with bromocriptine. As suggested by the pattern of serum prolactin concentrations monitored in the subset of 40 women, the rebound breast activity frequently observed after stopping bromocriptine (day 14) may be related to prolactin secretion rebound, ${ }^{7}$ a phenomenon which was much less pronounced in women receiving cabergoline. The rate of true rebound symptoms in women treated with bromocriptine (24\%) was in keeping with data given by the manufacturer (18$40 \%$ ). To ensure against rebound lactation it has even been suggested that bromocriptine $(2.5 \mathrm{mg}$ daily $)$ should also be given during the third postpartum week. ${ }^{6}$

The rates of complete success achieved in the present study with both cabergoline $(78 \%)$ and bromocriptine $(69 \%)$ were somewhat lower than that reported in previous studies. Previous experience with cabergoline is limited. Only one large dose finding trial has been performed, with a complete success rate of $90 \%$ in the 40 women in the puerperium receiving $1 \mathrm{mg}$ of the drug. ${ }^{16}$ The higher success rate in that study may be related to the relatively low number of subjects evaluated. On the other hand, the previously reported rate of complete success for bromocriptine ranged between $70 \%$ and $90 \%$ in several studies, but was $74 \%$ in the largest one, which was performed in 370 women, ${ }^{8}$ a figure similar to that observed in our study. In contrast with most other studies the present investigation applied the intention to treat analysis. The lower success rates were probably due to more rigorous evaluation criteria and methods of analysis. In fact, the failure rate was only $7 \%$ (which includes women who stopped taking the drugs because of intolerance or different reasons) in both treatment arms, and many subjects defined as having partial success had only one mild or moderate symptom, usually milk secretion, which generally lasted only one or two days. In clinical terms therefore the success rate was acceptable.

With reference to the safety of the two drugs the women treated with cabergoline had considerably less adverse events ( 25 events in 22 women) thän those treated with bromocriptine ( 44 events in 36 women). The rate of women with adverse events with bromocriptine $(27 \%)$ was consistent with that reported by the manufacturer (23\%). ${ }^{9}$ The observed side effects were almost all typical of the pharmacological class for both drugs and usually occurred during the first day of treatment or at least within the first three days. Nausea was rarely reported in those taking cabergoline, and no cardiovascular symptoms occurred after the third day in this treatment arm.

In conclusion, a single dose of $1 \mathrm{mg}$ of cabergoline was as effective as bromocriptine $2.5 \mathrm{mg}$ given twice daily for 14 days in inhibiting puerperal lactation. However, the new drug had an appreciably lower rate of rebound breast activity during the third postpartum week and was associated with considerably fewer adverse events than bromocriptine. The single dose treatment during the first postpartum day eliminates any problem of compliance, which may be an issue with treatments lasting two to three weeks in women in the puerperium. These important advantages should make cabergoline the drug of choice for inhibition of lactation.

Members of the group were:

Professor R Rolland and Dr W de Goeij (Nijmegen, The Netherlands); Drs C Nappi and G Colace (Naples, Italy); Drs A Cabellero-Gordo and I L Caballero-Diaz (Madrid, Spain); Drs L Falsetti and E Galbignani (Brescia, Italy); Drs G B Melis and A Paoletti (Pisa, Italy); Drs F Beguin and A Gianoni (Geneva, Switzerland); Drs A Vokaer and C Mongouya (Brussels, Belgium); Drs M Thiery and P Defoort (Ghent, Belgium); Dr M Steiner (Feiburg, Germany); Dr W Volker (Bielefeld, Germany); Dr G Thorbert (Kalmar, Sweden); Dr J Huber (Vienna, Austra); Drs G Piscitelli, M Lassus, A Petroccione, and C Ferrari (Milan, Italy).

1 Pepperell RJ. Suppression of lactation. Med F Aust 1986;144:37-9.

2 Kochenour NK. Lactation suppression. Clin Obstet Gynecol 1980;23:1045-59. 
3 Markin KE. Wolst MD. A comparative controlled study of hormones used in he prevention of postpartum breast engorgement and lactation. Am $7 \mathrm{Obstet}$ Gynecol 1960;80:128-37.

4 Daniel DG, Campbell H, Turnbell AC. Puerperal thromboembolism and suppression of lactation. Lancet 1967;ii:287-92.

5 Tindall VR. Factors influencing puerperal thrombo-embolism. fournal of Obstetrics and Gynaecology of the British Commonwealth 1968;75:1324-7.

6 Rolland R. Use of bromocriptine in the inhibition of puerperal lactation. Drugs 1979;17:326-36.

7 Peters F, Del Pozo E, Conti A, Breckwoldt M. Inhibition of lactation by a longacting bromocriptine. Obstet (jynecol 1986;67:82-5.

Duchesne C, Leke R. Bromocriptine mesvlate for prevention of postpartum lactation. Obstet (jynecol 1981;57:464-7.

9 Parlodel S. Physician's desk reference. 43rd ed. New York: Medical Economics, 1989.

10 Crosignani PG, Lombroso GC, Caccamo A, Reschini E, Peracchi $M$ Suppression of puerperal lactation by metergoline. Obstet Gynecol 1978;51: Suppre.

11 Van Dam LJ, Rolland R. Lactation-inhibiting and prolactin-lowering effect of lisuride and bromocriptine: a comparative study. Eur f Obstet Gynecol lisuride and bromocriptine:

2 Lancranjan I, Rolland R, L'Hermite M. Inhibition of lactation with depot bromocriptine. Ann NY Acad Sci 1986;464:473-7.
13 Di Salle E, Ornati G, Briatico G. FCE 21336, a new ergoline derivative with a Sotent and long-acting lowering effect on prolactin secretion in rats. Findocring lost 1982,5 (suph 1 ): 45 .

14 Ferrari C, Barbieri C, Caldara R, et al. Long-lasting prolactin-lowering effec of cabergoline, a new dopamine agonist, in hyperprolactinemic patients. f Clin Endocrinol Metab 1986;63:941-5.

15 Melis GB, Mais V, Paoletti AM, Benvenuti F, Gambaccioni M, Fioretti P. Prevention of puerperal lactation by a single oral administration of the new prolactin-inhibiting drug, cabergoline. Obstet Gynecol 1988;71:311-4.

16 Caballero Gordo A, Lopez-Lazareno N, Calderay M, Caballero Gordo JL, Mancheno E, Sghedoni D. Cabergoline: oral single dose inhibition of puerperal lactation. F Reprod Med (in press).

17 Blackwelder WC. "Proving the null hypothesis" in clinical trials. Controlled Clin Trials 1982;3:345-5

18 Dunnet $\mathrm{CW}$, Gent $\mathrm{M}$. Significance testing to establish equivalence between treatments, with special reference to data in the form of $2 \times 2$ tables. Biometrics 1977;33:593-602.

19 Mantel N, Haenszel W Statistical aspects of the analysis of data from retrospective studies of disease. F Natl Cancer Inst 1959:22:719-48.

20 Miller RG. Simultaneous statistical inference. New York: Springer-Verlag, 1981.

(Accepted 12 March 1991)
Icelandic Heart

Association, Lagmula 9,

Reykjavik, Iceland

Nikulas Sigfusson, MD,

chief physician

Helgi Sigvaldason, PHD,

statistician

Inga Ingibjörg

Gudmundsdottir, BSC,

research assistant

Ingibjörg Stefansdottir, BSC, research assistant

Thorsteinn Thorsteinsson,

MSC, chief biochemist

Icelandic Nutritional

Council, Armula 1a,

Reykjavik, Iceland

Laufey Steingrimsdottir,

PHD, nutritional physiologist

Department of Medicine, Reykjavik City Hospital,

108 Reykjavik, Iceland

Gunnar Sigurdsson, MD,

chief physician

Correspondence to:

Dr Sigurdsson.

BMf 1991;302:1371-5

\section{Decline in ischaemic heart disease in Iceland and change in risk factor levels}

Nikulas Sigfusson, Helgi Sigvaldason, Laufey Steingrimsdottir, Inga Ingibjörg Gudmundsdottir, Ingibjörg Stefansdottir, Thorsteinn Thorsteinsson, Gunnar Sigurdsson

\section{Abstract}

Objective-To monitor trends in mortality and morbidity due to ischaemic heart disease and compare these with observed levels of risk factors from population surveys.

Design-Analysis of trends in death rates from ischaemic heart disease in Iceland compared with expected rates computed from population surveys. Risk factor levels together with $\beta$ factors obtained from Cox's regression analysis were used to compute expected death rates. Trends in morbidity due to acute myocardial infarction were assessed and secular trends in dietary consumption compared with trends in cholesterol concentrations.

Setting-Reykjavik, Iceland (total population 250000 ; over half the population live in Reykjavik).

Subjects -12814 randomly selected residents in the Reykjavik area aged 45-64 (6623 men, 6191 women; $72 \%$ and $80 \%$ of those invited).

Main outcome measures-Age adjusted rates of myocardial infarction and deaths from ischaemic heart disease. Expected risk from risk factor levels (smoking, total serum cholesterol concentration, systolic blood pressure) at each unique survey visit.

Results-Mortality from ischaemic heart disease has decreased by $17-18 \%$ since 1970 . During 1981-6 the myocardial infarction attack rate in men under 75 decreased by $23 \%$. A decrease occurred in the level of all three major risk factors after 1968. The fall in the serum cholesterol concentration coincided with a reduction in consumption of dairy fat and margarine. The calculated reduction in risk for the age group 45-64 was about $35 \%$, which was closely similar to the observed decrease in mortality due to ischaemic heart disease in that age group.

Conclusion-The reduction in mortality from ischaemic heart disease was substantially due to a decreased incidence of myocardial infarction and could be attributed largely to the reduction in risk factors.

\section{Introduction}

The mortality from ischaemic heart disease has been declining in some countries and holding steady in others, but in a few countries it continues to rise. ${ }^{1}$ Time trends or secular trends in ischaemic heart disease mortality have been difficult to analyse because they are usually based on mortality statistics with little or no information about the individual changes in the pattern of risk factors.

Mortality from ischaemic heart disease in Iceland is similar to that in other Scandinavian countries. ${ }^{1}$ We have analysed the trends in mortality and morbidity due to ischaemic heart disease in Iceland in relation to changes in $(a)$ the three major risk factors for the disease as documented in population surveys from 1968 to 1988 - namely, smoking, total serum cholesterol concentration, and systolic blood pressure-and (b) the consumption of saturated fats.

\section{Subjects and methods}

\section{ASCERTAINMENT OF MORTALITY FIGURES}

Information was obtained from all death certificates from 1951 to 1988 on file in the Statistical Bureau of Iceland by using the following codes of the International Classification of Diseases: 1951-60, ICD (sixth revision) code 420 ; 1961-70, ICD (seventh revision) code 420; 1971-80, ICD (eighth revision) codes 410-413; 1981-8, ICD (ninth revision) codes 410-414. These codes have been suggested to be the most equivalent for ischaemic heart disease in the different editions. ${ }^{2}$ All death certificates were reviewed and coded by an official pathologist. Necropsy had been carried out in $30-40 \%$ of cases.

\section{REGISTER OF MYOCARDIAL INFARCTION 1981-6}

During 1981-6 all episodes of acute myocardial infarction in people aged 25-74 anywhere in Iceland were registered by the Icelandic study group of the World Health Organisation's MONICA project (multinational monitoring of trends and determinants of cardiovascular disease). ${ }^{3-5}$ Diagnostic criteria included symptoms, electrocardiograms, enzyme activities, and necropsy findings compatible with definite or possible myocardial infarction (category I or II). ${ }^{45}$ External quality control of event registration was performed by the WHO's reference centre in Dundee. Registrations included all occurrences of acute myocardial infarction (and sudden ischaemic cardiac death), but also, as separate categories, first and recurrent infarctions (more than 28 days apart). The proportion of cases excluded because of inade- 